\title{
Desenvolvimento da conceituação sobre a escrita mediado pela construção de mapas conceituais em uma rede de comunicação online: alguns resultados
}

\author{
Patrícia Behling Schäfer ${ }^{\mathrm{i}}$ - PPGIE/LEC/UFRGS - patricia@ lec.ufrgs.br \\ Léa da Cruz Fagundes - PPGIE/LEC/UFRGS - leafagun@ufrgs.br \\ Alex Fernando Teixeira Primo - PPGCOM/UFRGS - aprimo@ ufrgs.br \\ Alberto J. Cañas - IHMC/USA - acanas@ihmc.us
}

Resumo. O presente artigo propõe um método de intervenção voltado ao desenvolvimento da conceituação de estudantes sobre a escrita. A iniciativa sustenta-se na integração de mapas conceituais a construções textuais de alunos em uma rede de produção de notícias. A análise é realizada com base na triangulação de dados referentes aos níveis de desenvolvimento da escrita linear, à taxonomia topológica e à taxonomia semântica de mapas conceituais. Os resultados alcançados permitem inferir um grau de desenvolvimento solidário no que tange às duas formas representacionais investigadas, favorecendo tomadas de consciência no processo de revisão com vistas ao aprimoramento estrutural e semântico dos registros.

Palavras-chave: conceituação, escrita, comunicação, mapas conceituais.

\section{Conceptualization on written language mediated by the construction of concept maps in a news production network: some results}

\begin{abstract}
This paper presents an intervention method focused on students' conceptualization on written language. The proposal rests on the integration of concept maps to textual constructions of students in a news production network. The analysis is carried out based on the triangulation of data concerning levels of development of linear writing, as well as topological and semantic taxonomies for concept maps. The results indicate a reciprocal development with regard to both representation types, favoring consciousness-raising in the process of revising texts, in order to improve semantic and structural aspects of written language.
\end{abstract}

Keywords: conceptualization, writing, communication, concept maps.

\section{Introdução}

A presente proposta é contextualizada pela participação do LEC/UFRGS (Laboratório de Estudos Cognitivos do Instituto de Psicologia da Universidade Federal do Rio Grande do Sul ${ }^{1}$ no programa federal PROUCA (Um Computador por Aluno) ${ }^{2}$. O programa, lançado em 2007 e atualmente em sua segunda fase piloto, examina a possibilidade de distribuição de laptops educacionais, integrada à conexão com a Internet, a alunos e professores de escolas públicas do País como um meio de promoção de melhorias na educação.

Entre as diversas atividades realizadas no decurso da participação no Programa e com vistas a criar um campo de estudo e aplicação de uma nova abordagem sobre a escrita escolar, o LEC deu início, ainda na primeira etapa do PROUCA, ao planejamento da criação de uma rede de mídias integradas em que crianças e adolescentes, orientados por seus professores, pudessem se organizar como autores de informações dirigidas às suas comunidades, valendo-se da mobilidade, da conectividade e de recursos provenientes dos laptops. A esta proposta foram integradas, em 2011, a

\footnotetext{
${ }^{\mathrm{i}}$ Bolsista da CAPES - Processo n ${ }^{\circ}$ 8484/11-2.
} 
utilização de mapas conceituais (MCs) e a aplicação sistemática de entrevistas orientadas pelo Método Clínico Piagetiano (PIAGET, 2005), constituindo-se o projeto de tese de uma das autoras do presente artigo.

A iniciativa de criação de uma rede de comunicação voltada à produção de notícias sustenta-se na liberdade de expressão como facilitadora da exteriorização do pensamento, de modo que os alunos ofereçam indicadores quanto à sua aprendizagem em um ambiente que não se destina à avaliação quantitativa, mas a trocas cooperativas e solidárias. O mapa conceitual, por sua vez, configura-se em um recurso profícuo para a explicitação das ligações lógicas do pensamento, permitindo o acompanhamento dos processos de conceituação acerca dos mais diversos temas. Além disso, em razão da possibilidade de uma formatação não hierárquica, gera representações dinâmicas do conhecimento, sempre suscetível a mudanças e novas conexões.

$\mathrm{O}$ referido projeto de tese buscou investigar como um instrumento de representação do pensamento como o mapa conceitual, utilizado no panorama de uma rede de comunicação voltada à produção de informações, poderia se refletir sobre a conceituação de estudantes sobre a escrita, com ênfase nos aspectos semântico e estrutural, a partir do acompanhamento do desenvolvimento da coerência e da coesão de registros lineares. O presente artigo exibe parte dos resultados da pesquisa ${ }^{3}$, focalizando produções e impactos do método de intervenção relacionados a alunos de quarto ano do ensino fundamental de nove anos.

\section{Descrição do método}

A fim de examinar os possíveis impactos da produção de MCs e da aplicação de entrevistas clínicas a eles referentes no contexto de uma rede de produção de notícias sobre a conceituação sobre a escrita, foram adotados os procedimentos expressos na figura 1 .

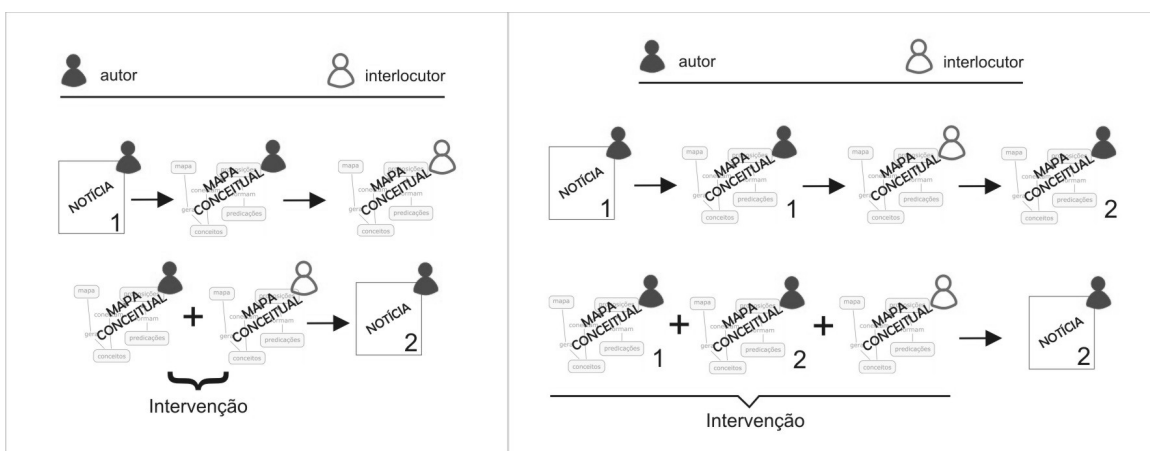

Figura 1 - Etapas do método de intervenção

Na primeira etapa de aplicação do método (quadro à esquerda), cada aluno, após escrever a primeira versão da notícia, elaborava um mapa conceitual sobre o texto próprio. Após a produção do mapa, sem intervenção da pesquisadora, o aluno era reportado ao seu texto com o intuito de realizar, se julgasse necessárias, alterações. Outro aluno era convidado a desenvolver um mapa sobre a primeira versão textual da notícia realizada pelo colega e, por último, procedia-se à intervenção, a fim de conduzir o aprendiz à escrita de uma nova versão. Tal etapa do método foi aplicada com 16 alunos de quarto ano do ensino fundamental de nove anos (com idade entre 9 e 11 anos), intitulados, neste artigo, grupo 1. Após a aplicação dos procedimentos descritos com o grupo 1, observou-se a possibilidade de aprimoramento do método a partir da 
inclusão da realização de uma segunda versão do mapa conceitual pelo autor de cada notícia (quadro à direita da figura 1). A segunda etapa do método foi aplicada com seis alunos de mesma série e faixa etária, intitulados, neste artigo, grupo 2.

Acompanhou-se a conceituação sobre a escrita a partir da consideração do nível estrutural e do nível semântico das produções, focalizando-se os aspectos de coerência e coesão, com base no aporte fornecido pela Linguística do Texto (KOCH, 2007; MARCUSCHI, 2008a, 2008b) e pela Epistemologia Genética (PIAGET, 1976). Foram analisados, assim, elementos como a articulação e a consistência interna dos segmentos do texto, recursos de conexão referencial e sequencial, realização de inferências, operações argumentativas e continuidade textual, unidade de sentido e encadeamento lógico dos tópicos discursivos, relacionados ao contexto comunicacional.

Com base na verificação da existência de impactos da produção de MCs sobre os registros lineares (seção 3, figura 5), tornou-se possível o estabelecimento de níveis de desenvolvimento textual, bem como de uma taxonomia semântica e de uma taxonomia topológica para o acompanhamento dos MCs. Buscou-se, desta forma, a obtenção de uma matriz que permitisse a análise dos dados provenientes dos diferentes tipos representacionais investigados. Os níveis elaborados para o acompanhamento do desenvolvimento do registro linear são exibidos na figura 2.

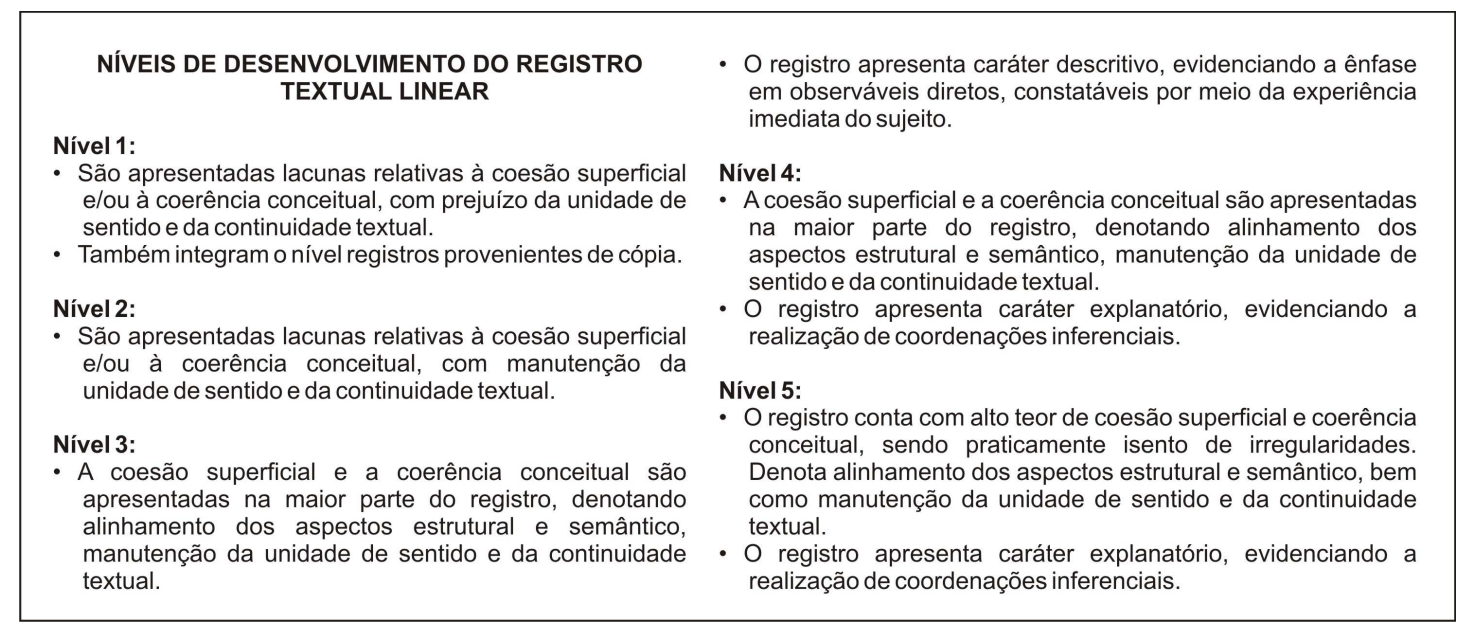

Figura 2 - Níveis de desenvolvimento do registro textual linear

Para a realização da análise focalizada na construção estrutural dos mapas conceituais, optou-se pela adoção da taxonomia topológica elaborada por Cañas et al. (2006) e Miller (2008), amplamente utilizada e validada pelo Projeto Conéctate al Conocimiento (MILLER, 2008). A taxonomia semântica dos MCs teve como suporte o conceito de interação apresentado pela Epistemologia Genética (PIAGET, 1976). Considerou-se, além da compreensão da estrutura de conceitos e proposições constituintes do mapa conceitual, a realização de interações de tipo 1 (relativas exclusivamente aos observáveis diretos, acessíveis pela experiência imediata dos sujeitos) e a realização de interações de tipo 2 (em que são constatadas também coordenações inferenciais). Os níveis das taxonomias topológica e semântica de MCs são exibidos nas figuras 3 e 4 . 
TAXONOMIA TOPOLÓGICA DE MAPAS CONCEITUAIS (CAÑAS et al., 2006; MILLER, 2008)

- Nível 0: (a) textos predominam sobre conceitos; (b) não há frases de ligação; (c) a estrutura é linear (0-1 pontos de ramificação).

- Nível 1: (a) conceitos predominam sobre textos; (b) faltam metade ou mais das frases de ligação; (c) a estrutura é linear (0-1 pontos de ramificação).

- Nível 2: (a) conceitos predominam sobre textos; (b) faltam menos da metade das frases de ligação; (c) há poucas ramificações ( 2 pontos).
- Nível 3: (a) não há textos; (b) não faltam frases de ligação; (c) o nível de ramificações é intermediário (3-4 pontos); (d) há menos de três níveis hierárquicos.

- Nível 4: (a) não há textos; (b) não faltam frases de ligação; (c) o nível de ramificações é alto (5-6 pontos); (d) há três ou mais níveis hierárquicos.

- Nível 5: (a) não há textos; (b) não faltam frases de ligação; (c) o nivel de ramificações é alto (5-6 pontos); (d) há três ou mais níveis hierárquicos; (e) há 1 ou 2 links cruzados.

- Nível 6: (a) não há textos; (b) não faltam frases de ligação; (c) o nível de ramificações é muito alto (7 ou mais pontos); (d) há três ou mais níveis hierárquicos; (e) há mais de 2 links cruzados.

Figura 3 - Taxonomia topológica de mapas conceituais

TAXONOMIA SEMÂNTICA DE MAPAS CONCEITUAIS

- Nível 1: Mapa denota ausência de compreensão da estrutura de conceitos e de proposições, e elementos não apresentam encadeamento lógico ou unidade de sentido.

- Nível 2: Mapa denota compreensão lacunar da estrutura de conceitos e de proposições, mas elementos apresentam encadeamento lógico, remetendo a uma sequenciação frásica.

- Nível 3: São produzidas proposições, embora permaneça a ocorrência de conexões que não geram sentenças.

\section{Mantêm-se a unidade de sentido e o encadeamento lógico.}

- Nível 4: Mapa denota reconhecimento da estrutura de conceitos e de proposições em grande parte das conexões, mas prevalecem observáveis diretos nas ligações efetuadas, constatáveis por meio da experiência imediata do sujeito.

- Nível 5: Mapa denota reconhecimento da estrutura de conceitos e de proposições em grande parte das conexões, apresentando coordenações inferenciais e implicações lógicas no decurso da produção.

Figura 4 - Taxonomia semântica de mapas conceituais

Estabelecidos os níveis para a análise dos textos lineares e dos MCs produzidos, são apresentados, na próxima seção, alguns dos resultados obtidos.

\section{Resultados}

Para o desenvolvimento do estudo, fez-se necessário, primeiramente, proceder a um levantamento que indicasse a existência ou a ausência de impactos da produção de MCs sobre os registros textuais lineares, assim como, se e quando existentes, os resultados de tais impactos sobre a composição do texto, no sentido de uma efetiva revisão da produção ou, por outro lado, da realização de ajustes que não implicassem reais mudanças em sua estrutura inicial. Caracterizaram-se como impactos a análise ou referenciação de elementos dos MCs que não se mostravam presentes no primeiro texto e passavam a ser exibidos na segunda versão do registro, bem como a revisão textual a partir de tomadas de consciência ${ }^{4}$ (PIAGET, 1976) desencadeadas ou facilitadas pela produção do mapa conceitual e pela posterior intervenção. O levantamento descrito é apresentado na figura 5. 


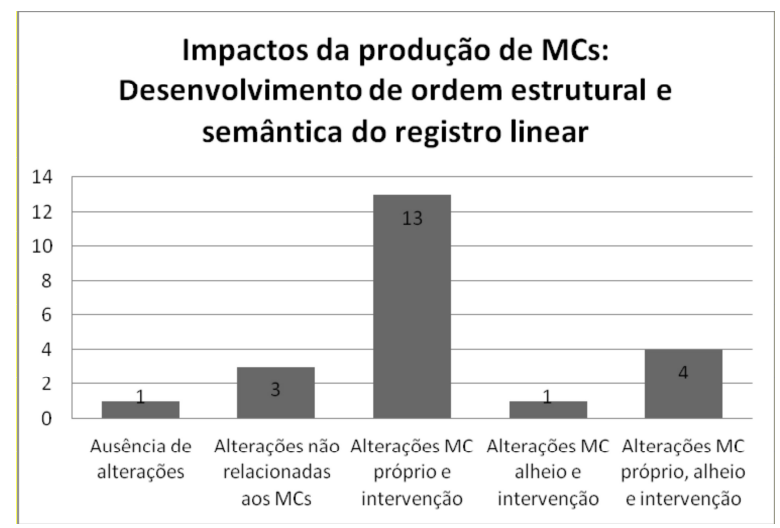

Figura 5 - Impactos da produção de MCs sobre o registro linear

Do total de 22 produções de alunos dos grupos 1 e 2 da pesquisa, 18 demonstraram impactos a partir da construção de MCs (próprios e/ou alheios) seguidos da intervenção orientada pelo Método Clínico Piagetiano no contexto da rede de produção de notícias. A maior parcela dessas produções - 13 - apresentou impactos da produção de mapas conceituais por seus próprios autores. Quatro das produções revelaram impactos provenientes tanto da produção de MCs pessoais como da produção de mapas conceituais por colegas, no interior da proposta de interlocução do método. Uma produção evidenciou impactos provenientes apenas da produção do mapa conceitual por um colega. Em três das produções, as alterações realizadas não se mostraram diretamente relacionadas à elaboração dos $\mathrm{MCs}$ e/ou à intervenção. Finalmente, uma das produções manteve-se inalterada após a produção dos mapas conceituais e a condução da intervenção.

O primeiro levantamento realizado permitiu inferir a pertinência da adoção do método na faixa etária considerada, com maiores reflexos provenientes das produções em MC dos próprios autores. O segundo levantamento - expresso no gráfico da figura 6 - apresenta os níveis referentes ao desenvolvimento do registro textual linear na primeira e na segunda versão das produções dos sujeitos da pesquisa ${ }^{5}$.

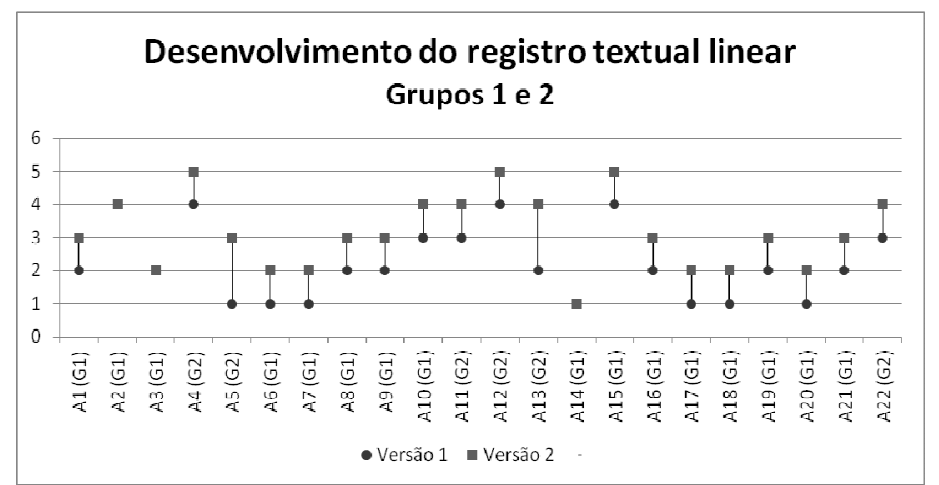

Figura 6 - Desenvolvimento do registro textual linear

Conforme as progressões observadas, cinco alunos manifestaram em suas produções mudança de nível 1 para nível 2 da primeira para a segunda versão do registro textual linear, passando a contar com unidade de sentido ou dispor de caráter autoral, a despeito da manutenção de lacunas relativas à coesão superficial e/ou à coerência conceitual. Um aluno transitou do nível 1 para o nível $3 \mathrm{em}$ relação ao registro linear, denotando também crescimento dos aspectos estrutural e semântico em sua produção. Seis alunos apresentaram da primeira para a segunda versão do registro linear mudança de nível 2 para nível 3, permitindo inferir o aprimoramento da coerência 
e de elementos coesivos, a manutenção da unidade de sentido e o caráter descritivo da produção, suportada majoritariamente por observáveis diretos. A produção de um aluno revelou o trânsito do nível 2 para o nível 4, e produções de três alunos manifestaram mudança de nível 3 para nível 4, passando a exibir também a realização de coordenações inferenciais. Três alunos apresentaram em seus registros textuais lineares o progresso de nível 4 para nível 5, denotando caráter explanatório e a realização de coordenações inferenciais, bem como o alcance de alto teor de alinhamento dos aspectos estrutural e semântico na versão final da produção. Finalmente, três alunos não exibiram mudança de nível.

Os gráficos das figuras 7 e 8 exibem as frequências de níveis referentes à taxonomia topológica e à taxonomia semântica dos MCs nas produções sobre texto próprio.

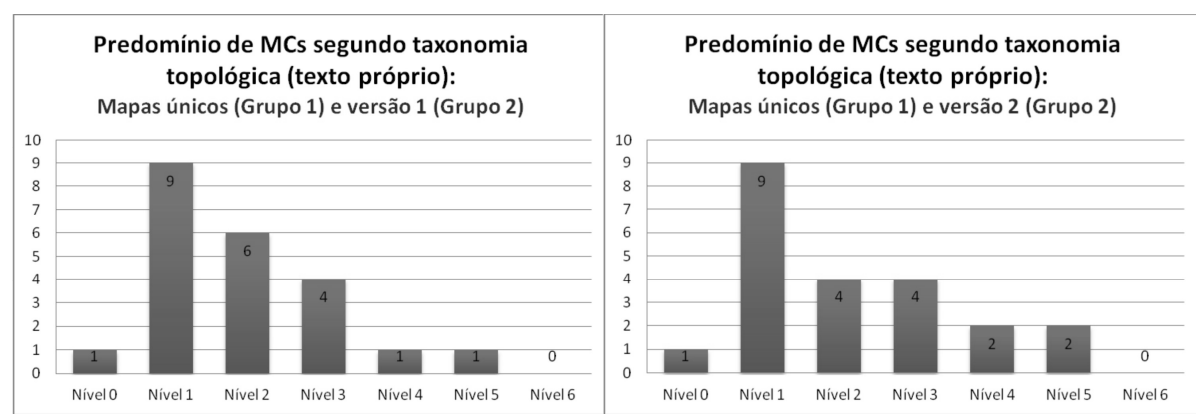

Figura 7 - Predomínio de níveis segundo taxonomia topológica - texto próprio

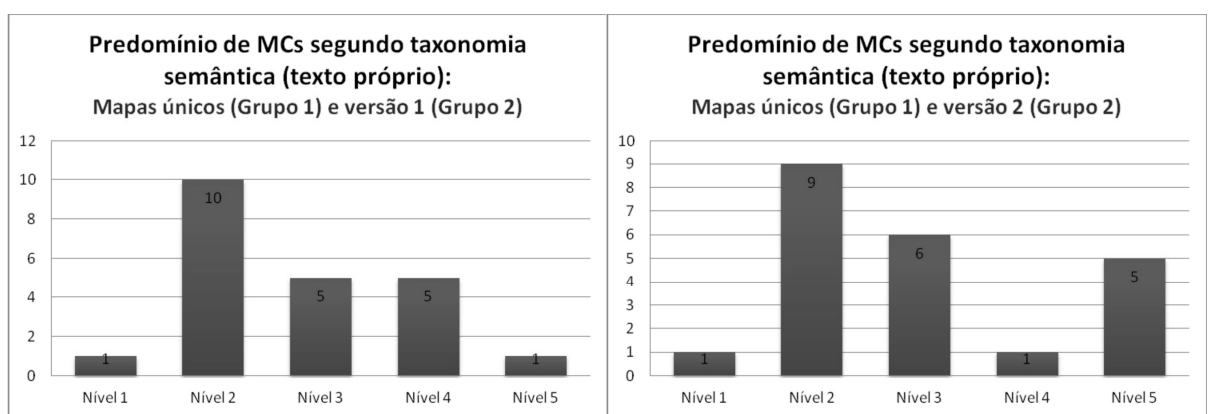

Figura 8 - Predomínio de níveis segundo taxonomia semântica - texto próprio

Conforme a taxonomia topológica, se considerados os níveis individualmente, demonstra-se o predomínio de alunos - nove ao todo - no nível 1, que pressupõe a compreensão, ainda que parcial, da estrutura do mapa conceitual, uma vez que palavras ou pequenas expressões são utilizadas nas caixas ao invés de textos longos, e frases de ligação são igualmente empregadas. Apenas um dos alunos evidenciou incompreensão da estrutura topológica básica do mapa conceitual. Os primeiros mapas (considerandose a primeira versão do grupo 2) evidenciam que mais da metade dos alunos - doze dos 22 estudantes investigados - já revelavam em suas produções nível 2 ou superior, incluindo frases de ligação em mais da metade dos arcos, pontos de ramificação a partir de conceitos ou frases de ligação e diferentes níveis hierárquicos. Considerando-se a segunda versão do grupo 2 , tem-se ainda uma distribuição mais homogênea dos alunos entre os níveis 2 e 5 - quatro alunos nos níveis 2 e 3 e dois alunos nos níveis 4 e 5 , respectivamente - indicando maior frequência de ramificações e níveis hierárquicos, a possibilidade da ocorrência de links cruzados e, desde o nível 3, a ausência de lacunas relacionadas às frases de ligação. Nenhum dos alunos manifestou nível 6 na taxonomia topológica. 
Considerando-se o caráter semântico das produções, resultados semelhantes foram observados. Evidenciou-se uma alta concentração de produções de nível 2, e metade das produções ao menos, considerando-se tanto a versão 1 como a versão 2 da produção do grupo 2, revelou nível semântico 3 ou superior, denotando a competência de construção de proposições ao menos em parte das conexões estabelecidas e a manutenção da unidade de sentido. Entre a versão 1 e a versão 2 da produção do grupo 2 evidenciou-se, ainda, um salto qualitativo em relação à construção de coordenações inferenciais nas ligações, manifesto na transição de quatro das produções de nível 4 para nível 5. Novamente, apenas um dos alunos demonstrou, paralelamente à incompreensão da estrutura de conceitos e de proposições, uma produção sem unidade de sentido. No que tange à produção do mapa conceitual sobre o texto alheio, observou-se um predomínio de níveis ligeiramente mais baixos quando comparados aos resultantes da produção sobre texto próprio (SCHÄFER et al., 2012).

No que se refere à análise dos níveis de desenvolvimento individual considerando-se texto e MC sobre texto próprio, verificou-se a compatibilidade dos resultados quando comparadas as diferentes propostas taxonômicas aplicadas. Nas três propostas de triangulação (texto linear x taxonomia semântica de MCs, texto linear x taxonomia topológica de MCs e taxonomia semântica x taxonomia topológica de MCs), a maior parte dos alunos revelou em suas produções diferença de até um nível. Assim como na análise pertinente à produção de MCs sobre o texto próprio, resultados próximos foram observados na comparação das diferentes propostas taxonômicas estabelecidas acerca da construção sobre o texto alheio.

Apresenta-se, na figura 9, um exemplo de produção e de mudanças operadas por uma aluna do grupo 2 .

TEXTO - VERSÃO 1

Por que comer cenoura é importante para o nosso corpo?

A cenoura possui anticancerígeno que ajuda a proteger 0 corpo do câncer, a cenoura tem betacaroteno que ajuda pele não envelhecer, a cenoura também combate as infecções e a cenoura diminui o colesterol A cenoura tem fósforo potássio cálcio sódio e vitaminas A B2 B3 C Fonte de fibras e Minerais.

MC - TEXTO PRÓPRIO/ VERSÃO 1

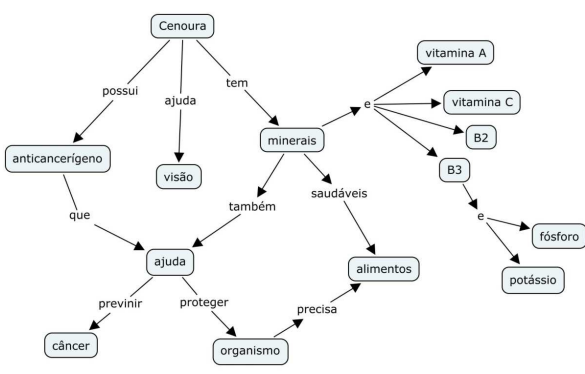

TEXTO - VERSÃO 2

Por que comer cenoura é importante para o nosso corpo?

A cenoura possui betacaroteno que ajuda a visão e ajuda a pele e também é um poderoso anticancerígeno que previne o câncer. A cenoura é um vegetal que contribui para aumentar a imunidade do nosso organismo, e a cenoura diminu o colesterol do nosso sangue, a cenoura tem fonte de fibras, minerais, fósforo, potássio, cálcio, sódio e vitaminas A, B2, B3 e C,A Cenoura tem Betacaroten Que ajuda a pele a não envelhecer e ajuda no bronzeamento da pele,E ajuda os olhos e a retina (que faz parte dos olhos).

MC - TEXTO PRÓPRIO/ VERSÃO 2

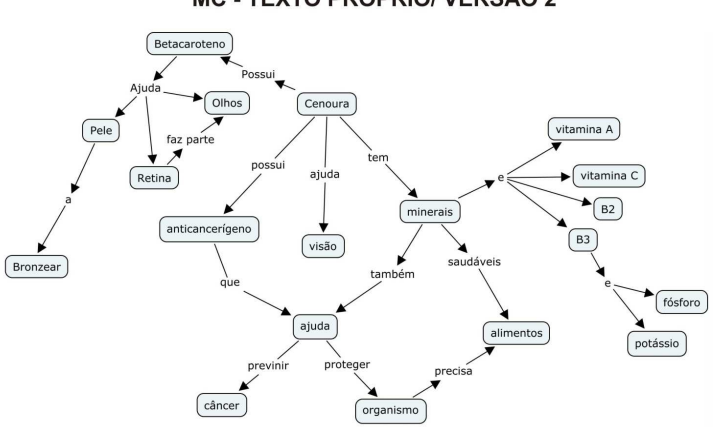

Figura 9 - Exemplo de produção em MC e texto linear

A aluna exibe, tanto na primeira como na segunda versão da produção em $\mathrm{MC}$, nível topológico 5. A segunda versão aproxima-se muito do nível 6 , não alcançado apenas em razão do número de ramificações (inferior a sete). Em relação ao nível semântico, há um crescimento de 4 para 5 da primeira para a segunda versão. $\mathrm{O}$ mapa, desde a primeira versão, exibe unidade de sentido, e o entendimento da aluna quanto à estrutura de proposições é manifesto em um grande número de conexões, a despeito de algumas ligações não verbais. Observa-se, ainda, um grande número de ramificações e a 
presença de links cruzados. Os MCs anunciam o alcance de complexidade estrutural e semântica, que impactam a produção textual por meio da realização de coordenações inferenciais e do acréscimo de informações, sobretudo em relação à substância Betacaroteno e aos seus desdobramentos quanto à imunidade e proteção do organismo. A segunda versão textual apresenta também aprimoramento em relação à ligação dos tópicos discursivos (apesar de algumas repetições lexicais), denotando uma melhor conexão sequencial, exibida na rearticulação dos segmentos do texto. Observa-se, assim, a modificação do nível 4 para o nível 5 na produção textual linear da aprendiz.

Importantes tomadas de consciência foram também observadas no decurso do processo de intervenção, ainda que parte delas não tenha se refletido imediatamente sobre a estrutura do MC. O exemplo apresentado nas figuras 10 e 11 ilustra a situação descrita.

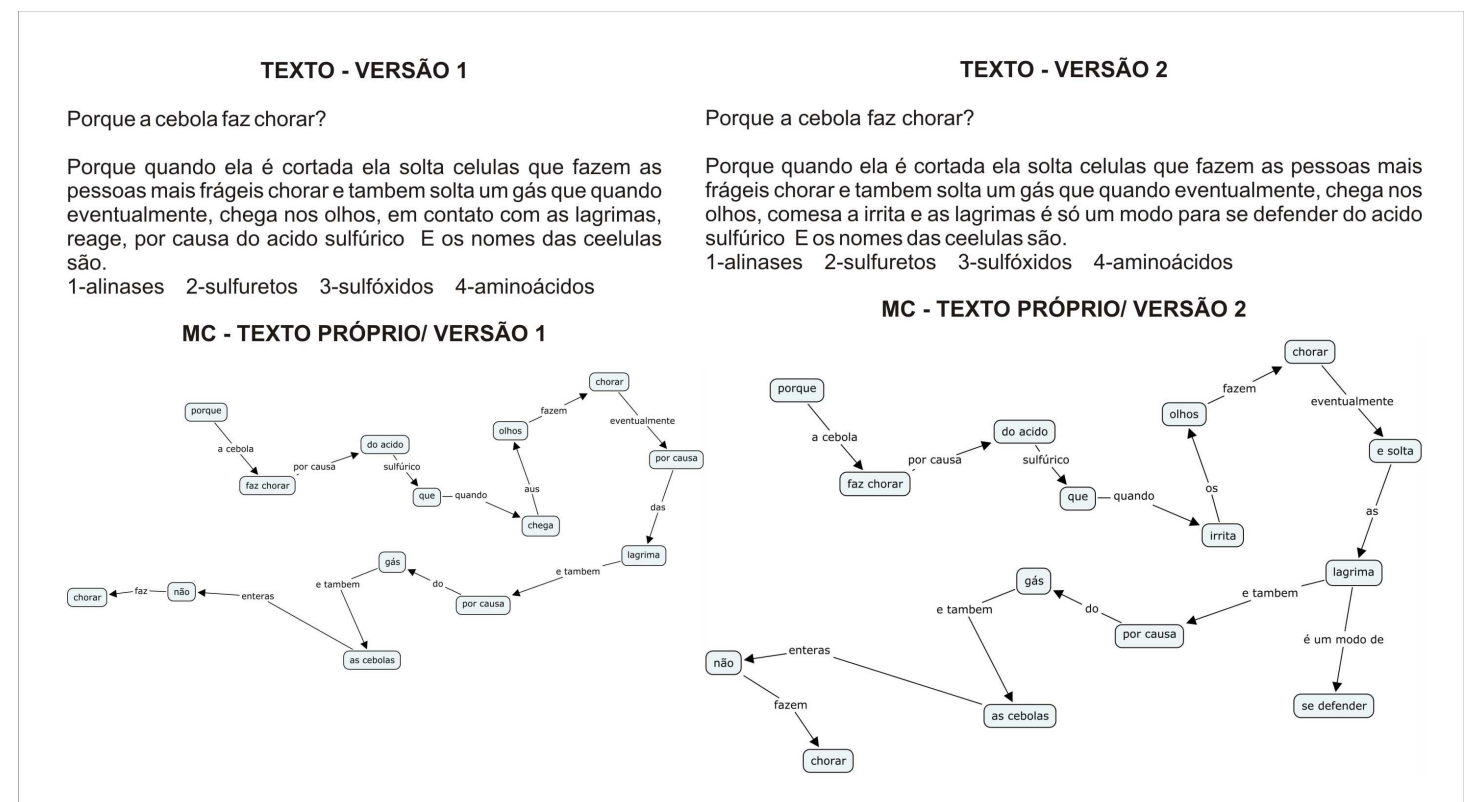

Figura 10 - Exemplo de produção em MC e texto linear

INTERVENÇÃO - TEXTO PRÓPRIO

$P:$ Qual foi a questão que levantou o problema?

A: Foi aqui 'ó', cebola faz chorar: por que a cebola faz chorar, no caso.

$P:$ É por causa das lágrimas?

A: Não.

P: E o que a gente pode colocar ali ao invés de "por causa", por exemplo? A expressão por causa dá a entender que é o motivo, não é?
A:É.

$P:$ E tem alguma outra coisa que pode nos fazer entender que "provoca" e não é "por causa"? A: Que irrita os olhos!

$P:$ Acho uma informação bem legal.

A: É que, quando o gás chega nos olhos, para se livrar do ácido sulfúrico, a gente chora. As lágrimas são um modo de se proteger.

Figura 11 - Intervenção clínica sobre a produção

O aluno buscava, em sua pesquisa, responder à pergunta "Por que a cebola faz chorar?". Depreendia-se, de sua produção linear, compreensão acerca do tema proposto. No entanto, despontava uma lacuna da primeira versão do MC: a informação de que o ácido sulfúrico e as lágrimas provocariam o "choro", sem explicitação da relação de causa e efeito. Possivelmente, na fonte de pesquisa consultada, o conceito de lágrima contemplasse a presença do líquido produzido pelas glândulas lacrimais sem referência estrita ao "transbordamento" de seu excesso. No MC e na intervenção, contudo, a noção apresentada pelo aluno parece referir-se a lágrimas como sinônimo de choro, problemática solucionada na escrita da segunda versão do registro linear, em que passam a ser entendidas, para efeito da questão de pesquisa, como resultado da irritação 
de terminações nervosas do olho e como modo de defesa do efeito do ácido, formado na ocasião do contato do gás emitido com a camada lacrimal. Há, assim, progresso da coerência, demonstrado na nova ligação estabelecida entre os tópicos discursivos, vinculado ao desenvolvimento coesivo, evidenciado por meio da revisão do processo de sequencialização. A reescrita reflete-se, igualmente, sobre a estrutura topológica da segunda versão do MC, principiando-se o processo de ramificação, ainda que em grau insuficiente para o alcance do nível 2. Em relação à taxonomia semântica, o aluno transita do nível 2 para o nível 3 da primeira para a segunda versão de sua produção, dando início ao processo de construção de proposições.

\section{Conclusões}

Foi possível, por meio do método de intervenção, inferir impactos sobre a conduta de revisão por meio da consideração das produções em mapa conceitual em um contexto de rede de produção de informações, empreendida pela maior parte dos aprendizes participantes da pesquisa. Os resultados encontrados também permitiram a visualização de um grau de desenvolvimento solidário no que se refere à conceituação sobre o registro textual linear e à elaboração dos MCs. As conexões elaboradas nos mapas conceituais mostraram-se suscetíveis a um novo grau de abstração quando na condição de objeto de reflexão no decurso do desenvolvimento do texto linear.

As produções denotaram um esforço de revisão sistemático, em sua maior parte com impactos sobre o caráter de coesão e coerência, e consequentes reflexos sobre a estrutura e o sentido comunicado pelo texto. Tais reflexos foram provenientes, sobretudo, das produções sobre texto próprio; em relação à produção do mapa conceitual pelo interlocutor, o método não apresentou impactos de mesma ordem. A adoção de uma taxonomia topológica integrada a uma taxonomia semântica na análise das construções em mapa conceitual favoreceu a investigação de casos em que, apesar da não compreensão plena da estrutura de conceitos e proposições, havia mudanças qualitativas significativas que antecediam a tomada de consciência no que tange à operação com predicações. A compreensão da estrutura topológica básica do mapa conceitual e a construção de sentido evidenciadas pela maior parte dos aprendizes durante as intervenções revelaram, assim, a aplicabilidade do trabalho com uma representação alternativa ao registro textual linear no intuito de deflagrar ou favorecer tomadas de consciência que se refletissem sobre a conceituação acerca do mesmo.

Observou-se, ainda, a relevância da oportunidade de construção de uma segunda versão do mapa conceitual sobre o texto próprio, procedimento adotado com o grupo 2 de alunos da pesquisa. O salto qualitativo da primeira para a segunda versão das produções elaboradas pelo grupo, a realização de coordenações inferenciais e o reconhecimento da estrutura de conceitos e de proposições em grande parte das conexões foram indicadores da pertinência da realização de diferentes versões do MC criadas por um mesmo autor, ainda que o processo de interlocução proposto no método favorecesse o acesso a diferentes representações, provenientes de diferentes autores.

Destaca-se, ao final, a importância da aplicação de um método integrado, incluindo a prática da intervenção sobre a produção oriunda do interesse do aluno em um contexto rico para a exploração. O panorama de produção de informações, por exemplo, permitiu o levantamento de questões de interesse dos aprendizes, bem como a socialização das descobertas com públicos que igualmente lhes trouxessem significado. A construção de mapas conceituais, a interlocução por eles mediada e as intervenções focalizadas nos aspectos semântico e estrutural de MCs e textos lineares tiveram, assim, 
a base de conexão necessária para o acompanhamento e o auxílio à conceituação sobre a escrita.

\section{Referências}

CAÑAS, A. J.; NOVAK, J. D.; MILLER, N. L.; COLLADO, C.; RODRÍGUEZ, M.; CONCEPCIÓN, M.; SANTANA, C.; PEÑA, L. Confiabilidad de una taxonomía topológica para mapas conceptuales. In: II International Conference on Concept Mapping, San José, Costa Rica, 2006.

KOCH, I. V. A inter-ação pela linguagem. São Paulo: Contexto, 2007.

MARCUSCHI, L. A. Da fala para a escrita: atividades de retextualização. 9. ed. São Paulo: Cortez, 2008a.

Produção textual, análise de gêneros e compreensão. São Paulo: Parábola Editorial, 2008b.

MILLER, N. L. An exploration of computer-mediated skill acquisition in concept mapping by in-service Panamanian public elementary school teachers. Doctoral Program on the Information and Knowledge Society, Universitat Oberta de Catalunya, 2008.

PIAGET, J. A equilibração das estruturas cognitivas: problema central do desenvolvimento. Rio de Janeiro: Zahar Editores, 1976.

A representação do mundo na criança. São Paulo: Idéias e Letras, 2005.

SCHÄFER, P. B.; CAÑAS, A. J.; FAGUNDES, L. C; PRIMO, A. F. T. Impacts of an intervention method mediated by the construction of concept maps in a news production network on students' conceptualization of written language. In: V International Conference on Concept Mapping, Msida, Malta, 2012.

\section{Notas:}

${ }^{1}$ O LEC/UFRGS foi responsável por orientar a experiência pré-piloto do Programa UCA no Rio Grande do Sul e, na segunda fase do piloto, é um dos centros coordenadores da formação de professores.

${ }^{2}$ Disponível em: <http://www.uca.gov.br/institucional/>.

3 Resultados parciais da tese de doutorado foram também apresentados no artigo Impacts of an intervention method mediated by the construction of concept maps in a news production network on students' conceptualization of written language (SCHÄFER, P. B.; CAÑAS, A. J.; FAGUNDES, L. C; PRIMO, A. F. T. In: CMC 2012 - V International Conference on Concept Mapping, Msida, Malta, 2012).

${ }^{4}$ O processo de tomada de consciência (PIAGET, 1976) dá conta da ciência sobre os novos instrumentos de raciocínio utilizados pelo sujeito, sendo característico da transição da abstração reflexionante para a abstração refletida.

5 Sujeitos representados pela inicial "A" (aluno) + n, com numeração crescente conforme ordem alfabética considerando-se o primeiro nome de cada aprendiz. G1 e G2 referem-se a grupo 1 e grupo 2, respectivamente. 